\section{Practice Standards Scheme}

\section{Pam Mosedale}

The Practice Standards Scheme (PSS) is a voluntary initiative to accredit veterinary practices in the UK. Through setting standards and carrying out regular assessments, the scheme aims to promote and maintain the highest standards of veterinary care.

The PSS, first launched in 2005, had a major relaunch in 2015 and has been a great success, with a current membership comprising well over half of all veterinary practice premises. The scheme is reviewed by the
Practice Standards Group (comprised of representatives of all the major veterinary organizations) every 5 years and the 2020 review has introduced some changes to the scheme.

If your practice is part of the PSS or thinking of joining and you are keen to keep ahead of the game, come along to hear PSS Lead Assessor Pam Mosedale give an overview of the changes to the Small Animal Standards at Core, GP and Veterinary Hospital level, and the Awards.

\section{KEY LEARNING OBJECTIVES}

- Keep up to date with changes to accreditation standards

- Keep up to date with changes to the Voluntary Awards Scheme

\section{Graduate Outcomes Consultation: where are we and what's happening next?}

\section{Linda Prescott-Clements}

In November 2018 the Royal College of Veterinary Surgeons (RCVS) launched the Graduate Outcomes Consultation. This consultation grew out of the joint RCVS and British Veterinary Association (BVA) Vet Futures research project, which found that there was often a mismatch between the expectations of veterinary graduates and the reality of veterinary practice. The consultation asked for the views of all veterinary surgeons, veterinary nurses, veterinary students and other stakeholders in a broad range of areas related to how veterinary students are educated and trained, and how recent graduates are prepared and supported into life in practice.

The consultation had a fantastic response, with nearly 4000 individuals, plus organisational responses, focus groups and individual interviews. In this session Professor Stephen May, the Chair of the Graduate Outcomes Working Group, will give an overview of the findings of the consultation and a description of how we are moving the work forward for the benefit of the profession.

\section{KEY LEARNING OBJECTIVES}

- Be able to tell others what is at the centre of the RCVS Day 1 Skills Model and how this relates to veterinary education
- Describe an Entrustable Professional Activity and how they are a useful learning tool for new graduates

- Understand the role of extramural study (EMS) within the veterinary degree

\section{MULTIPLE CHOICE QUESTIONS}

1. Why are the Day One Competences in place?
(A) To prepare recent graduates so that they possess the skills required on completion of the Professional Development Phase
(B) Ensuring that veterinary students have the knowledge, skills, attitudes and behaviours that we believe veterinary surgeons should have upon graduation
(C) To prepare veterinary students for life in a veterinary practice
(D) For universities to monitor veterinary students' progress

2. What does EPA stand for?
(A) Entrustable Professional Activity
(B) Entirely Possible Answer
(C) European Protection Agency
(D) Engaged Problem Alignment

3. What is the purpose of EMS?
(A) For veterinary students to gain experience in areas that they are unfamiliar with
(B) To allow veterinary students to practice core skills learned on intramural rotations
(C) To help out at busy practices
(D) To give lecturers time off teaching 